\title{
Research on Development Path of Wenzhou Intelligent Manufacturing under Trend of Emerging Industry
}

\author{
Zhuo Jing \\ Wenzhou Vocational \& Technical College, Wenzhou. 325035 \\ zhuojing@qq.com
}

Keywords: Emerging Industry; Intelligent Manufacturing; Path

\begin{abstract}
Based on researching the development path of Wenzhou intelligent manufacturing industry, to understand the overall development of Wenzhou in this field, find out the shortcomings in development, and then propose suggestions for further improving Wenzhou intelligent manufacturing. All these are of great significance and lay foundation for better cultivating and developing the industry of intelligent manufacturing equipment.
\end{abstract}

\section{Introduction}

The $13^{\text {th }}$ Five-Year National Strategic Plan for Development of Emerging Industries puts forward five emerging industries that will be emphatically developed in China, of which information technology, life health, and intelligent manufacturing industries rank among the top three. At present, the traditional industrial powers around the world are vigorously researching and developing intelligent manufacturing technology, as well as its accompanying multi-disciplinary integration technology. Germany's "Industry 4.0", American "Industrial Internet", and EU's "2020 Growth Strategy" are all national strategies formulated for the advent of the intelligent manufacturing era. Chinese government introduced the Intelligent Manufacturing Development Plan (2016-2020) at the end of 2016. Dr. Huang Pei, deputy director of Wenzhou Intelligent Manufacturing Research Institute, interpreted the strategy of implementing intelligent manufacturing, and Dr. Cai Fenghua from Wenzhou Advanced Manufacturing Technology Research Institute of Huazhong University of Science and Technology explained the digitalized journey of manufacturing industry in the era of intelligent manufacturing. Wenzhou's manufacturing industry is mainly concentrated in equipment manufacturing, textile and electronic information, which are not only the advantages and realistic foundations of Wenzhou's industrial economy, but also the key fields for future intelligent transformation and promoting construction of industrial powerful cities. Only by committing to intelligent products and equipment, and intelligent production, and integrating the new generation of information technology (e.g. Internet of Things, big data, and cloud computing) with manufacturing activities (e.g. enterprise design, production, management, and service) can Wenzhou lead its manufacturing industry to develop toward high-end and improve overall image as well as competitiveness.

\section{Path Design}

\subsection{Facilitating digitalized transformation in Wenzhou}

The dynamic perception, processing and analysis capabilities needed in the process of developing traditional manufacturing into intelligent manufacturing require enterprises to transform and upgrade their own technologies through digitalized technologies and equipment. Meanwhile, enterprises shall regard digitalization as the core driving force for the transformation and upgrading of traditional manufacturing into intelligent manufacturing. 


\subsection{Accelerating Integrated Interconnection in Wenzhou}

The integrated interconnection includes integration and interconnection. The system where information and function are inter-connected and coordinated not only helps integration of various resources and data, but also realizes convenient, efficient and centralized management.

\subsection{Perfecting high-tech coordinated fusion in Wenzhou}

The fusion methods include cross-fusion, embedded fusion, composite fusion, and cross-border fusion. As the driving force for developing traditional manufacturing into intelligent manufacturing, fusion enables traditional manufacturing to continue to develop and upgrade, generates more economic growth points, and acts as an important idea for the evolution of traditional manufacturing.

\subsection{Driving technological innovation in Wenzhou}

Technological innovation is the core of intelligent manufacturing, and innovation originates from technological evolution. Meanwhile, in order to achieve integrated interconnection in equipment and control layers of manufacturing, high-tech support is needed because technological innovation can drive high-tech applications.

\subsection{Applying the new generation of information technology}

The intelligent virtual manufacturing platform is mainly supported by big data under the Internet environment. Big data is an important factor driving the simulation manufacturing platform to accurately simulate or execute production. The manufacturing enterprises may present a leap-forward, non-linear transformation and upgrading of intelligent manufacturing.

\subsection{Promoting construction of intelligent talents}

Talent construction refers to cultivating or introducing professional talents and managers into the key areas of intelligent manufacturing that are in urgent demand, such as high-end CNC machine tools and industrial robots. As a comprehensive system engineering, intelligent manufacturing requires both advanced skilled workers with special skills and leading talents proficient in advanced research and development, and new business models. Therefore, it is necessary to pay attention to the construction of talent team, explore to establish introduction and training incentive mechanism of intelligent manufacturing urgently-needed talents, and strengthen the construction of high-level talent team in intelligent manufacturing. On the one hand, by creating excellent living, scientific research and entrepreneurial environments, overseas students and talents mastering key core technologies and independent intellectual property rights will be attracted to work and start businesses in Wenzhou. On the other hand, it is required to give full play to the platform role of enterprises, research institutes, universities, vocational colleges and other training institutions, innovate talent training models, improve the quality of talent training, expand the scale of talent training, and introduce as well as cultivate a batch of high-level leading talents, technical professionals and highly skilled personnel in intelligent manufacturing as soon as possible.

\subsection{Enhancing the effect of attracting investment and introducing high-tech intelligent enterprises}

E.g. Introducing Gree Intelligent Equipment, Haier Intelligent Manufacturing and Germany advanced manufacturers to facilitate the upgrading of Wenzhou manufacturing industry. 


\subsection{Striving to develop producer services}

In addition, it is also needed to vigorously develop producer service; give full play to the characteristics of producer service, such as knowledge, innovation, professionalism and coordination; provide manufacturing enterprises with high-tech and efficient industrial supporting service through the producer service supporting system that is closely connected, functionally perfect and coordinated developed; reduce the production and operation costs of manufacturing enterprises; improve the customer response and flexible production capacity of manufacturing enterprises; realize the coordinated development of manufacturing and producer services. Manufacturing industry is a strategic pillar industry of Wenzhou, so deepening industrial transformation and upgrading is a strategic and overall issue concerning social and economic development. That is to say, industrial transformation and upgrading shall avoid weaknesses; strengthen innovation of technology, production mode and organization; actively build ecosystem of intelligent manufacturing industry; continuously improve advanced manufacturing capabilities and levels; realize the transformation and upgrading of manufacturing industry.

\section{Overall Framework}

The framework is shown in Fig. 1

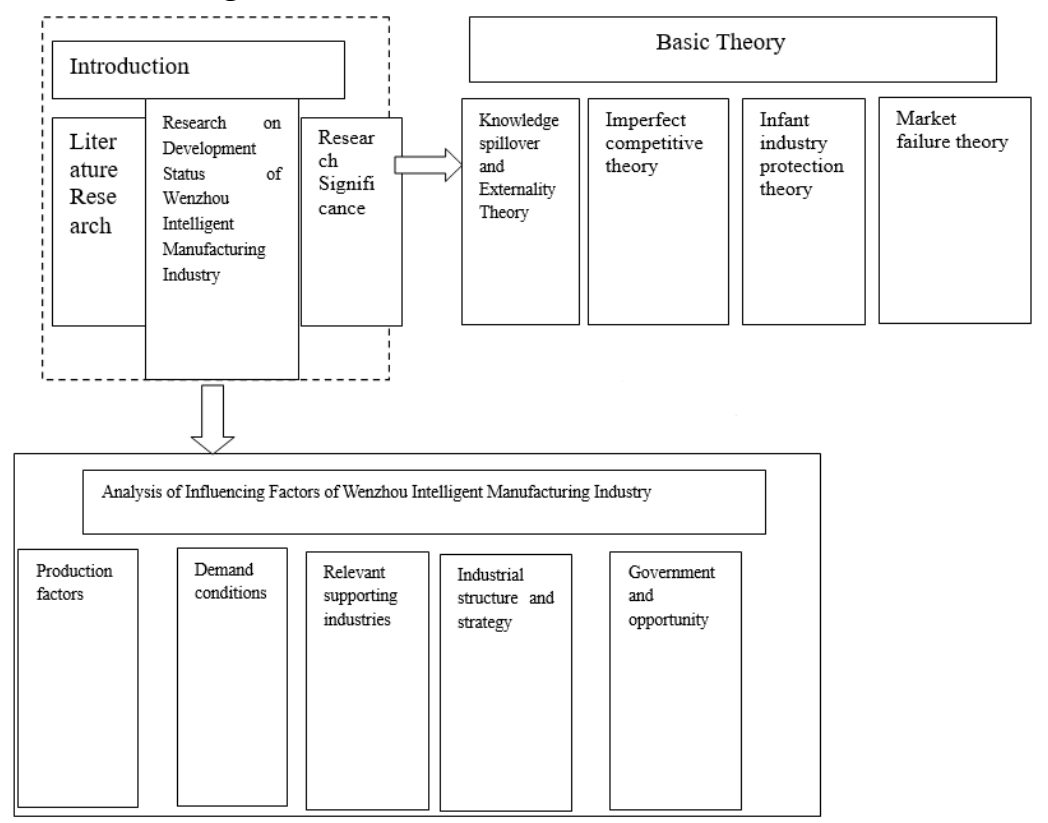

Fig.1 Framework

Based on the continuously developed multidisciplinary fields, including physical analysis method, computer technology, predictive algorithms, artificial intelligence, big data and cloud computing, the future intelligent algorithms fully integrate the independent analysis function of artificial intelligence, which is the embodiment of the comprehensive analysis and decision of multiple teams. Moreover, the analysis has a single point and extensibility, so as to better realize the large-scale analysis and decision making of intelligent manufacturing, and achieve the sharing of information results. The path research is shown in Fig. 2.

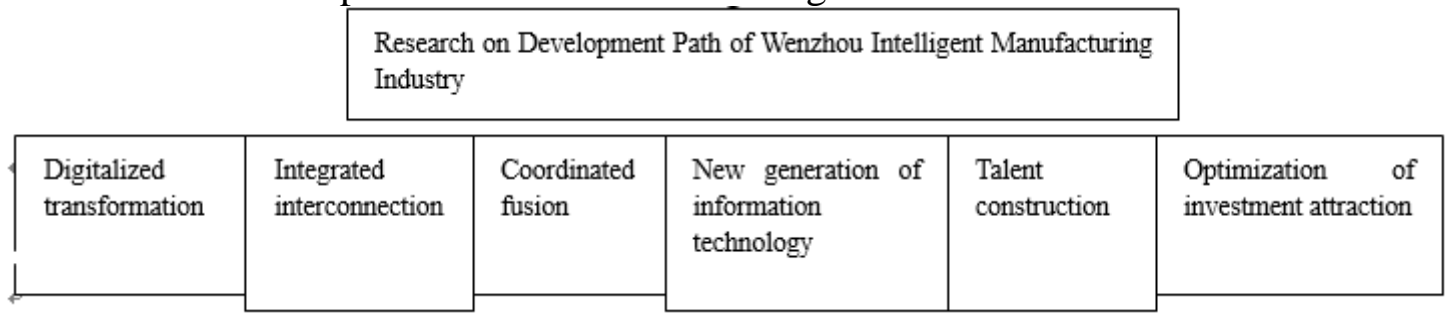

Fig.2 Path Research 


\section{Essence of Intelligent Manufacturing}

In essence, intelligent manufacturing is a mass customization production model that is built for horizontal integration with suppliers, customers and partners realized through corporate information portals, along with the vertical integration within the enterprise. [3] Its operation involves many factors in endogenous system and exogenous environment.

\subsection{Customer Demands}

In the market environment with product homogenization and fierce competition, to successfully satisfy customers' individualized and differentiated needs has become a key factor for enterprises' survival and development. Therefore, it is the focus and starting point of the "customer-centric" mass customization to accurately obtain customers' potential demands, and meet customers' requirements and expectations with low cost and high efficiency.

\subsection{Collaborative Design}

Computer Supported Cooperative Works, CSCW, enables distributed team members to work together on the same platform so as to select, evaluate, send and receive product data; analyze product design; standardize and generalize component design; ultimately realize modularized assembly of products; and lay a solid foundation for subsequent synergistic supply as well as collaborative manufacturing.

\subsection{Collaborative Supply}

By building a supply chain network service platform, suppliers, manufacturers, distributors and users can dynamically share customer needs, product design, process documentation, supply chain planning, inventory and other information. In this way, they can quickly respond to any change in customer needs, modification and design, which minimizes inventory and improves operational efficiency.

\subsection{Collaborative Manufacturing}

Flexible Manufacturing System; based on organically integrating with virtual manufacturing concepts, FMS clarifies enterprises' roles and labor division in product structure; achieves production planning collaboration, supply coordination and parallel production among production enterprises; improves equipment utilization; shortens product production cycle; improves customer response speed; forms a dynamic production management that responds quickly according to market environment changes and personal consumption preferences.

\subsection{E-commerce}

The establishment of an interactive network sales platform and supply chain e-commerce system helps realize the network of core value chain such as sales, network procurement, network payment, logistics and quality tracking. The big data analysis of users' explicit requirements including demand cycles, purchasing preferences and account terms, as well as hidden needs associated with customer industry characteristics, geographical regions and industry scale not only contributes to effectively understanding and guiding customers' demands, but also provides guarantee for developing collaborative design, supply and manufacturing of customized products among customers, suppliers, manufacturers and service providers.

\subsection{Collaborative Service}

Customer Relationship Management, CRM, focuses on customers and the entire life cycle of 
product. Under the support of the supply chain network service platform, it timely collects the data of product operation status; carries out data sharing through service platform; conducts online diagnosis and monitoring of product operation status by combining with product intelligent operation and maintenance library; properly offers online consultation and service to problems and obstacles; creates new value for customers and enterprises. On the basis of realizing effective circulation of endogenous system, the ecosystem of intelligent manufacturing industry also needs the powerful guarantee by exogenous environmental system so as to realize the transformation, upgrading and development of manufacturing industry.

\subsection{Position of equipment manufacturing industry in manufacturing value chain}

Characterized by intensive technology, concentrated capital, high added value, and great driving force to related industries, equipment manufacturing industry is located in the high-end position in the manufacturing value chain. More than being an important indicator of a country's comprehensive competitiveness and core competence, it is also the backbone of China's future national economic development. However, compared with developed countries, China's equipment manufacturing enterprises have the following characteristics: firstly, lack of core competitiveness, and excessive dependence on developed countries' technological capabilities; secondly, locating in the low-end of value chain with low technical capital and meager profit in value creation. Therefore, China urgently needs to vigorously develop the equipment manufacturing industry, shorten the distance from developed countries, and upgrade equipment manufacturing enterprises. Starting with the theory of enterprise ecological niche, this paper comprehensively analyzes the achievements obtained by the experts and scholars conducting in-depth research on ecological niche theory, and the characteristics of equipment manufacturing industry. From the four ecological niche factor dimensions of demand, resources, culture and technology, and according to the specific quantifiable indicators, the ecological niche evaluation index system of equipment manufacturing enterprises is determined.

\section{Conclusion}

On the one hand, it means that staffs in the era of intelligent manufacturing will be collaborated in a broad sense. The personnel in different positions and places will be interconnected in real time; they use instant message to assist in intelligent product design, production and post-maintenance. On the other hand, when the intelligent manufacturing reaches a certain level, it will be accompanied by a comprehensive transformation of consumption and management structure. That is to say, the currently enterprise-led while consumers passively accepted production and consumption model will be completely changed to form a service-oriented intelligent manufacturing system. Consumers may become the masters of design, and the role of enterprises will be largely transformed into the helper of design and provider of the production facilities. Enterprises will have to fully consider and respect consumers' diversified individual needs, and create two new manufacturing models of "mass individualized customization" and "personalized scale customization" [10]. With the maturity of 3D printing, big data, cloud computing, and Internet of Things, manufacturing will be no longer limited to factories and workshops since individuals, families and community groups will also develop small-scale personalized manufacturing units, which can be interconnected and exchange data with enterprise intelligent control centers, so as to make entire social manufacturing model more intelligentized.

\section{Acknowledgements}

The project of Wenzhou philosophy and Social Science (18wsk335). 


\section{References}

[1]Sébastien Gebus,Esko Juuso,Kauko Leiviskä. Knowledge-based linguistic equations for defect detection through functional testing of printed circuit boards[J]. Expert Systems With Applications,2007,36(1).

[2]G. Harinath Gowd,M. Venugopal Goud,K. Divya Theja,M. Gunasekhar Reddy. Optimal Selection Of Machining Parameters In CNC Turning Process Of EN-31 Using Intelligent Hybrid Decision Making Tools[J]. Procedia Engineering,2014,97.

[3]Michael D. Nunez,Joachim Vandekerckhove,Ramesh Srinivasan. How attention influences perceptual decision making: Single-trial EEG correlates of drift-diffusion model parameters[J]. Journal of Mathematical Psychology,2016.

[4]Samuel H. Huang,Hong-Chao Zhang. Neural-expert hybrid approach for intelligent manufacturing: A survey[J]. Computers in Industry,1995,26(2).

[5]Qinglin Guo,Ming Zhang. A novel approach for multi-agent-based Intelligent Manufacturing System[J]. Information Sciences,2009,179(18).

[6]H.C.W. Lau,S.K. Tso,J.K.L. Ho. Development of an intelligent task management system in a manufacturing information network[J]. Expert Systems With Applications,1998,15(2).

[7]S. Minhas,C. Juzek,C. Lehmann,U. Berger. Development of Intelligent Decision Support System based on Unified Concept for Distributed Manufacturing Planning[J]. IFAC Proceedings Volumes,2013,46(9).

[8]W. Hufenbach,W.-J. Fischer,M. Gude,S. Geller,T. Tyczynski. Processing Studies for the Development of a Manufacture Process for Intelligent Lightweight Structures with Integrated Sensor Systems and Adapted Electronics[J]. Procedia Materials Science,2013,2.

[9]Felix T.S. Chan,Bing Jiang,Nelson K.H. Tang. The development of intelligent decision support tools to aid the design of flexible manufacturing systems[J]. International Journal of Production Economics,2000,65(1).

[10]R. Teti,S.R.T. Kumara. Intelligent Computing Methods for Manufacturing Systems[J]. CIRP Annals - Manufacturing Technology,1997,46(2).

[11]Azadeh Hassannejad Nazir,Hans Liljenström. A cortical network model of cognitive and emotional influences in human decision making[J]. BioSystems,2015,136.

[12]Michal Kremer-Asaf. How to Apply the Cybernetic Decision Making Model in Education?[J]. Procedia - Social and Behavioral Sciences,2015,209.

[13]Zeshui Xu. Group decision making model and approach based on interval preference orderings[J]. Computers \& Industrial Engineering,2013,64(3).

[14]Scott G. Heyler,Achilles A. Armenakis,Alan G. Walker,Donovan Y. Collier. A qualitative study investigating the ethical decision making process: A proposed model[J]. The Leadership Quarterly,2016,27(5).

[15]Bruce Tonn,Dorian Stiefel. Willow pond: A decentralized low-carbon future scenario[J]. Futures,2014,58.

[16]Sharad Chandra Srivastava,Alok Kumar Choudhary,Surendra Kumar,M. K. Tiwari. Development of an intelligent agent-based AGV controller for a flexible manufacturing system[J]. The International Journal of Advanced Manufacturing Technology,2008,36(7-8).

[17]Bo-hu Li,Bao-cun Hou,Wen-tao Yu,Xiao-bing Lu,Chun-wei Yang. Applications of artificial intelligence in intelligent manufacturing: a review[J]. Frontiers of Information Technology \& Electronic Engineering,2017,18(1).

[18]Jared M. Hotaling,Jerome R. Busemeyer. DFT-D: a cognitive-dynamical model of dynamic decision making[J]. Synthese,2012,189(1).

[19]H.C.W. Lau,Bing Jiang,W.B. Lee,K.H. Lau. Development of an Intelligent Data-Mining System for a Dispersed Manufacturing Network[J]. Expert Systems,2001,18(4).

[20]Robin Ramcharan. Singapore's Emerging Knowledge Economy: Role of Intellectual Property and its Possible Implications for Singaporean Society[J]. The Journal of World Intellectual Property,2006,9(3). 
[21]Zi-Jing Lin,Lin Li,Mary Cazzell,Hanli Liu. Atlas-guided volumetric diffuse optical tomography enhanced by generalized linear model analysis to image risk decision-making responses in young adults[J]. Human Brain Mapping,2014,35(8).

[22]Sivan Rapaport PhD,Moshe Leshno MD PhD,Lior Fink PhD. A design process for using normative models in shared decision making: a case study in the context of prenatal testing[J]. Health Expectations,2014,17(6).

[23]Rebecca A. Scott,Benjamin T. George,Victor R. Prybutok. A Public Transportation Decision-Making Model within a Metropolitan Area[J]. Decision Sciences, 2016,47(6).

[24]Darren Southwell,Reid Tingley,Michael Bode,Emily Nicholson,Ben L. Phillips. Cost and feasibility of a barrier to halt the spread of invasive cane toads in arid A ustralia: incorporating expert knowledge into model-based decision-making[J]. Journal of Applied Ecology,2017,54(1). 